\title{
Application of agar-fill method to estimate compartment capacity of gastrointestinal tract in Syrian hamsters (Mesocricetus auretus)
}

\author{
BY OSAMU SASAKI*, HISASHI SHINOHARA, TOSHIHIRO YAMAGISHI, \\ AKIRA NISHIDA AND YUTAKA MIZUMA \\ Department of Animal Science, Faculty of Agriculture, Tohoku University, Aoba-ku, Sendai 981, \\ Japan
}

(Received 21 June 1994-Revised 5 February 1996-Accepted 5 April 1996)

\begin{abstract}
In the present study we have developed the agar-fill method for the measurement of gastrointestinal-tract capacity (GTC) to replace the in vitro water-fill method. This would estimate GTC without using complex equipment and techniques, and can be applied to the measurement of GTC for small laboratory animals. We attempted to confirm the efficiency of the agar-fill method by investigating the relationship between dietary neutral-detergent fibre (NDF) content and GTC. The digestion trials were carried out using the Syrian hamster (Mesocricetus auretus). The trials were conducted using both sexes, two agegroups and three levels of dietary NDF with a cross-classified design. The size of each gastrointestinal organ was determined as tissue weight (TW) and GTC. The DM intake, digestible DM intake, DM digestibility, NDF digestibility, acid-detergent fibre (ADF) digestibility and digesta transit time were also measured. GTC increased with increasing NDF content of the diets. TW responded similarly to increasing NDF content, but the response was smaller than that of GTC. DM digestibility decreased with increasing NDF content of the diet. The digestible DM intake did not decrease with increasing NDF because DM intake increased with NDF content. Digesta transit time was not shorter of the high-NDFdiet group but DM intake increased with increasing NDF content. NDF digestibility did not differ significantly between low- and medium-NDF diets. ADF digestibility was low in the low-NDF-diet group. The digestion characteristics were highly correlated with TW and GTC, except for TW of small intestine. These correlations were higher with GTC than with TW. The results of the present study confirm previous findings suggesting that the agar-fill method is a useful means of estimating GTC for small laboratory animals.
\end{abstract}

Digestibility: Gastrointestinal-tract capacity: Retention time: Syrian hamsters

Enlargement of the gastrointestinal-tract capacity (GTC) with increasing neutral-detergentfibre (NDF) content in the diet has been reported by many authors (Kass et al. 1980; Pond et al. 1981 ; Stanogias \& Pearce, 1985; Gidenne, 1992). Stanogias \& Pearce (1985) suggested that the enlargement of the gastrointestinal tract might be a result of compensation to increase the animals' ability to utilize energy derived from dietary fibre. But these suggestions were not based on actual GTC measurement. GTC is a key factor in the study of digestive systems. The in vitro water-fill method has been the most popular method for measuring GTC. Herd \& Harrop (1978) applied this method in the measurement of GTC of the different compartments in brush-tailed possums (Trichosurus vulpecula) and rabbits. The advantage of the water-fill method is that the pressure is controlled accurately, and GTC is measured under similar pressure conditions to those in vivo. However, if part of the gastrointestinal tissue is damaged, even if the tear is very small, the water-fill method will

* Present address: Hokkaido National Agricultural Experimental Station, Toyohira-ku, Sapporo 062, Japan. 
not measure GTC. Furthermore, the water-fill method requires the end of the compartment to be tied. In the case of laboratory animals, the gastrointestinal tract is very small and delicate. It is difficult, therefore to tie the end of the compartment without damage. Thus, there is a need to develop a method for measuring GTC of laboratory animals. The purpose of the present study was to develop a new method for studying fibre digestion using Syrian hamsters (Mesocricetus auretus) fed on three diets with differing fibre contents.

\section{MATERIALS AND METHODS}

\section{Animals and management}

Seventy-two Syrian hamsters (thirty-six males and thirty-six females) were used. They were assigned to four groups by sex and two starting ages of 7 and 10 weeks. After they had been weaned at the age of 3 weeks they were randomly allocated to one of three dietary treatments within each group, with six animals in each dietary group. The diets used were diets commercially produced for mice (F2; Funabashi Farm Co., Ltd, Funabashi, Chiba, Japan) and guinea-pigs (GP1; Funabashi Farm Co., Ltd) and a lucerne (Medicago sativa) diet (LU; International Feed no. 1-00-023; Funabashi Farm Co., Ltd). GP1 contained about $400 \mathrm{~g}$ lucerne meal $/ \mathrm{kg}$, whereas F2 did not contain lucerne meal. The chemical compositions of the diets are shown in Table 1. Diets and water were available ad libitium. Animals were kept in an air-conditioned room $\left(24 \pm 1^{\circ}\right.$ and $55 \pm 10 \%$ relative humidity) with an artificial light-dark cycle (light off 19.00-05.00 hours).

\section{Digestion trials}

After weaning, thirty-six Syrian hamsters were fed on one of the experimental diets and at 7 or 10 weeks of age underwent a $7 \mathrm{~d}$ digestion trial. Animals were kept individually in metabolism cages for $8 \mathrm{~d}$ before the digestion trial started. Faeces were collected individually during the experiment. Faeces were analysed for DM, NDF and acid-detergent fibre (ADF) contents (Abe, 1988). Individual body weights were recorded at the end of the trial. The weight of the contents of the gastrointestinal tract was subtracted from body weight to reduce the effect among diets. For each animal, DM intake and digestible DM, NDF and ADF intakes were adjusted for metabolic body size (body weight ${ }^{\mathbf{0 . 7 5}}$ ) for statistical analysis.

\section{Rate of passage}

At $1 \mathrm{~d}$ before the start of the digestion trials at 7 weeks of age the digesta transit time was estimated using the method developed by Sakaguchi et al. (1987). After a $3 \mathrm{~h}$ fasting period the animals were fed on a Cr-containing diet (marked diet) for $2 \mathrm{~h}$. They were then fed on the unmarked diet. Faeces were collected at $1 \mathrm{~h}$ intervals for $10 \mathrm{~h}$ after the end of feeding the marked diet and also after 21 and $22 \mathrm{~h}$.

\section{Measurement of gastrointestinal-tract capacity}

GTC was measured directly at the end of the digestion trial. The gastrointestinal tract was separated into forestomach, glandular stomach, small intestine, caecum and colon. Tissue weight (TW) was measured after the contents of each compartment had been washed with physiological saline $(9 \mathrm{~g} \mathrm{NaCl} / 1)$ using a Pasteur pipette. The compartment was then filled with agar gel $(20 \mathrm{~g} / \mathrm{l})$ and weighed (weight of agar plus weight of gastrointestinal tissue; AWWG). The weight of agar (AWOG) was calculated by subtracting TW from AWWG (AWOG = AWWG -TW). GTC was obtained by dividing the density of agar $(\mathrm{g} / \mathrm{ml})$ by AWOG. A disposable syringe $(20 \mathrm{ml})$ was used for agar-filling. Before the syringe was attached to the gastrointestinal tissue, it was prepared as follows: (1) the melted agar was poured into the syringe from the open end and the piston fitted. The agar cooled and gelled 
Table 1. The chemical composition of the experimental diets* $(\mathrm{g} / \mathrm{kg})$

\begin{tabular}{|c|c|c|c|}
\hline & $\begin{array}{l}\text { Diet for mice } \\
\text { (F2) }\end{array}$ & $\begin{array}{l}\text { Diet for } \\
\text { guinea-pigs } \\
\text { (GP1) }\end{array}$ & $\begin{array}{c}\text { Lucerne (Medicago sativa) } \\
\text { diet } \\
\text { (LU) }\end{array}$ \\
\hline $\begin{array}{l}\text { DM }(\mathrm{g} / \mathrm{kg} \text { diet }) \\
\text { Chemical composition }(\mathrm{g} / \mathrm{kg} \mathrm{DM})\end{array}$ & 896.2 & 904.6 & $905-4$ \\
\hline Crude protein $(\mathrm{N} \times 6.25)$ & 202.0 & & 160.4 \\
\hline Crude fat & $\begin{aligned} 2020 \\
51.2\end{aligned}$ & $\begin{array}{r}238.8 \\
46.4\end{array}$ & $\begin{array}{r}169.4 \\
38.5\end{array}$ \\
\hline NDF & 173.5 & $\begin{array}{r}46.4 \\
301.2\end{array}$ & $\begin{array}{r}38.5 \\
484.8\end{array}$ \\
\hline ADF & 30.6 & 142.9 & 277.7 \\
\hline Lignin & $9 \cdot 0$ & $40 \cdot 1$ & 88.7 \\
\hline
\end{tabular}

NDF, neutral-detergent fibre; ADF, acid-detergent fibre.

* For details, see p. 834.

in the syringe; (2) a glass tube $(80 \mathrm{~mm} \times 2 \mathrm{~mm}$ i.d.) was attached to the top of the syringe, connecting it with a rubber tube. Each end of the tube was tapered and rounded. The glass tube was placed into the interior of the gastrointestinal tract. The edge of the gastrointestinal tract did not need to be tied. The agar was added by pushing the piston until the agar overflowed from the end of the gastrointestinal tract. It was then weighed (AWWG). GTC and TW were adjusted for metabolic body size for statistical analysis.

\section{Statistical analysis}

The effects of age, sex and diet were analysed using the general linear model (GLM) procedure of Statistical Analysis Systems (1985). The statistical model for GLM was:

$$
Y_{1 j k l}=M+A_{1}+S_{j}+D_{k}+e_{1 j k l} \text {, }
$$

where $Y_{i, j k 1}$ are dependent variables, $M$ is the overall mean, $A_{i}$ is the effect of starting age of digestion trials, $S_{j}$ is the effect of sex, $D_{k}$ is the effect of diet, and $e_{i j k 1}$ are residuals.

The least square means were analysed using the LSMEANS statement of GLM. The test of least significant differences was performed using the PDIFF option of the LSMEANS statement.

The correlation coefficients among TW, GTC and digestion characteristics were analysed using the correlation (CORR) procedure of Statistical Analysis Systems (1985).

\section{RESULTS}

Before the start of the experiment, seven Syrian hamsters were used to establish the relationship between GTC by the agar-fill method and GTC by the water-fill method. GTC of the caecum and colon for each animal was measured by both the agar-fill method and the water-fill method. The contribution ratio due to regression between the two methods for GTC was very high in the caecum $\left(R^{2} 0.91\right)$ and the colon $\left(R^{2} 0 \cdot 70\right)$. The regression for the caecum is shown in Fig. 1.

\section{Gastrointestinal-tract capacity and tissue weight}

The measurement of GTC, TW and body weight showed the relationships between these variables and the difference in dietary components. GTC and TW for all compartments were unaffected by sex and age. Sex, age and diet had significant effects on body weight $(P<0.0001)$. Body weight was highest with diet F2 and lowest with diet LU (Table 2). 


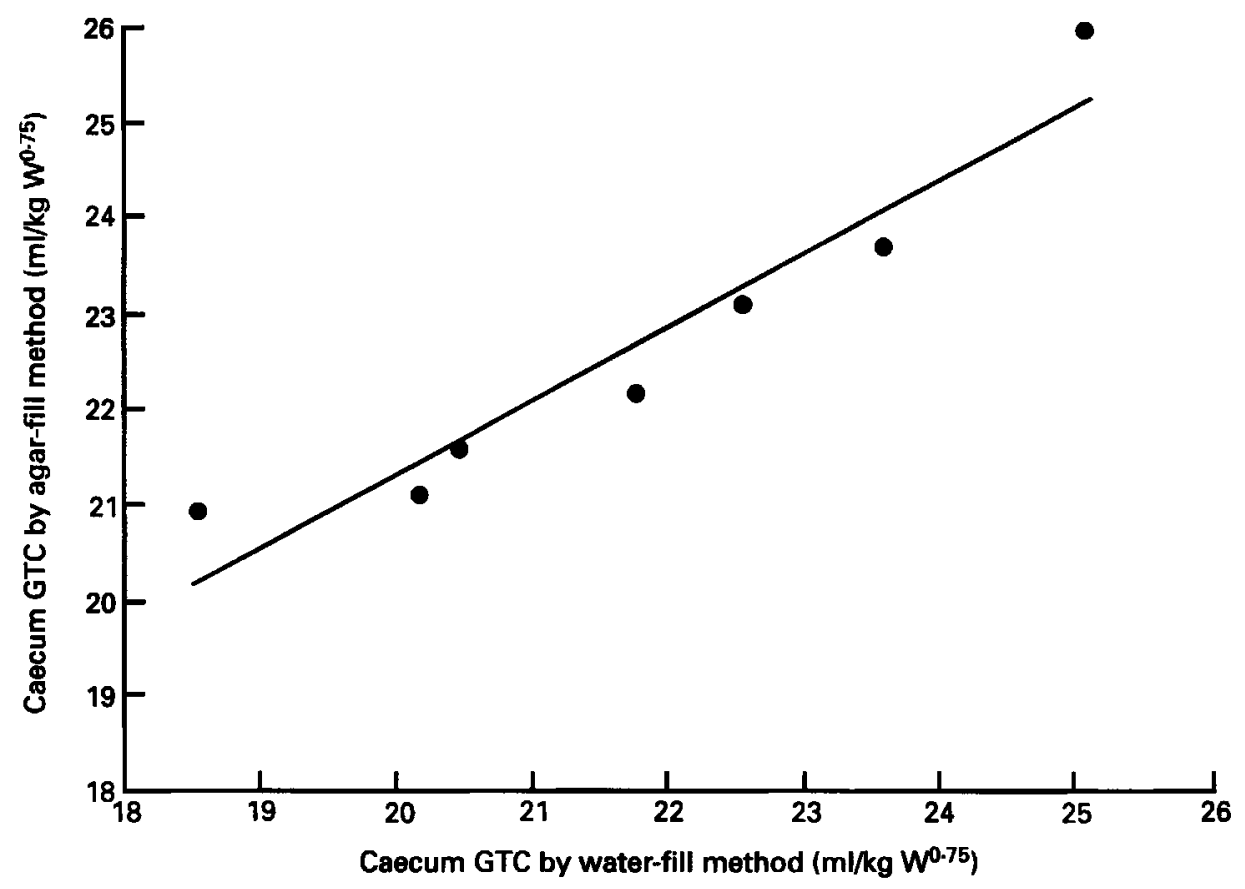

Fig. 1. Caecum gastrointestinal-tract capacity (GTC) determined by the agar-fill method v. caecum GTC determined by the water-fill method for Syrian hamsters (Mesocricetus auretus). For details of procedures, see pp. $834-835$. $\mathrm{W}^{0 \cdot 75}$, metabolic body size, where $\mathrm{W}$ is body weight. $R^{2} 0.091$.

Table 2. Least square means* for body weight $(W)$ and the capacity of gastrointestinal tracts (GTC) of Syrian hamsters (Mesocricetus auretus) given diets with differing neutraldetergent-fibre contents

(Mean values with their standard errors)

\begin{tabular}{|c|c|c|c|c|c|c|}
\hline \multirow[t]{2}{*}{$\operatorname{Diet} \uparrow \ldots$} & \multicolumn{2}{|c|}{ F2 } & \multicolumn{2}{|c|}{ GP1 } & \multicolumn{2}{|c|}{$\mathbf{L U}$} \\
\hline & Mean & SE & Mean & SE & Mean & $\mathrm{SE}$ \\
\hline $\begin{array}{l}\text { W (g) } \\
\text { TW (mg/kg W0.75) }\end{array}$ & $125 \cdot 9^{a}$ & $2 \cdot 1$ & $113 \cdot 7^{\mathrm{b}}$ & $2 \cdot 0$ & $77 \cdot 3^{\mathrm{c}}$ & $2 \cdot 0$ \\
\hline Forestomach & $7 \cdot 4^{\mathrm{a}}$ & $1-0$ & $9 \cdot 2^{\mathrm{a}}$ & $1 \cdot 0$ & $15 \cdot 8^{b}$ & $1 \cdot 0$ \\
\hline Glandular stomach & $15 \cdot 2^{\mathrm{a}}$ & $1 \cdot 0$ & $17 \cdot 2^{\mathrm{a}}$ & $1 \cdot 0$ & $26 \cdot 4^{b}$ & 1.0 \\
\hline Small intestine & $35 \cdot 5$ & $2 \cdot 7$ & $28 \cdot 5$ & $2 \cdot 6$ & $33 \cdot 1$ & $2 \cdot 6$ \\
\hline Caecum & $21 \cdot 5^{\mathrm{a}}$ & $1 \cdot 8$ & $23.9^{2}$ & $1 \cdot 8$ & $38 \cdot 8^{b}$ & 1.8 \\
\hline $\begin{array}{l}\text { Colon } \\
\left.\text { GTC (ml/kg W' }{ }^{0.75}\right)\end{array}$ & $33 \cdot 8^{\mathrm{a}}$ & $2 \cdot 1$ & $35 \cdot 0^{\mathrm{a}}$ & $2 \cdot 1$ & $49 \cdot 0^{b}$ & $2 \cdot 1$ \\
\hline Forestomach & $55 \cdot 1^{\mathrm{a}}$ & $4 \cdot 4$ & $64 \cdot 7^{a}$ & $4 \cdot 3$ & $102 \cdot 7^{\mathrm{b}}$ & $4 \cdot 3$ \\
\hline Glandular stomach & $53 \cdot 6^{\mathrm{a}}$ & 3.8 & $64 \cdot 1^{\mathrm{a}}$ & $3 \cdot 7$ & $93 \cdot 8^{b}$ & 3.7 \\
\hline Small intestine & $217 \cdot 7^{\mathrm{a}}$ & $9 \cdot 7$ & $247.0^{b}$ & $9 \cdot 5$ & $360.5^{e}$ & $9 \cdot 5$ \\
\hline Caecum & $298 \cdot 5^{x}$ & $25 \cdot 6$ & $467 \cdot 2^{b}$ & $25-1$ & $871 \cdot 3^{\circ}$ & $25 \cdot 1$ \\
\hline Colon & $206 \cdot 3^{\mathrm{a}}$ & $8 \cdot 4$ & $242 \cdot 3^{b}$ & $8 \cdot 3$ & $372 \cdot 7^{c}$ & $8 \cdot 3$ \\
\hline
\end{tabular}

a, b, c Mean values within rows with different superscript letters were significantly different $(P<0-05)$.

F2, mouse diet; GP1, guinea-pig diet; LU, lucerne (Medicago sativa) diet; TW, tissue wt; W $^{0.75}$, metabolic body size.

* Calculated using LSMEANS statement of GLM of Statistical Analysis Systems (1985).

$\uparrow$ For details of diets and procedures, see Table 1 and pp. 834-835 
Table 3. Least square means* of digestion characteristics of Syrian hamsters (Mesocricetus auretus) given diets with differing neutral-detergent-fibre (NDF) contents

(Mean values with their standard errors)

\begin{tabular}{|c|c|c|c|c|c|c|}
\hline \multirow[t]{2}{*}{ Diet... } & \multicolumn{2}{|c|}{$\mathbf{F} 2$} & \multicolumn{2}{|c|}{ GP1 } & \multicolumn{2}{|c|}{ LU } \\
\hline & Mean & SE & Mean & SE & Mean & SE \\
\hline DM intake $\left(g / d\right.$ per $\left.k g W^{0 \cdot 75}\right)$ & $1.573^{\mathrm{a}}$ & 0.032 & $1 \cdot 816^{\mathrm{b}}$ & 0.031 & $2 \cdot 742^{c}$ & 0.031 \\
\hline \multicolumn{7}{|l|}{ Intake digestible $\left(\mathrm{g} / \mathrm{d}\right.$ per $\left.\mathrm{kg} \mathrm{W}^{0.75}\right)$ of: } \\
\hline DM & $1 \cdot 331^{8}$ & 0.018 & $1 \cdot 306^{\mathrm{a}}$ & 0.018 & $1 \cdot 469^{b}$ & 0.018 \\
\hline NDF & $0 \cdot 126^{\mathrm{a}}$ & 0.006 & $0.255^{b}$ & 0.006 & $0.499^{\circ}$ & 0.006 \\
\hline ADF & $0.006^{\mathrm{a}}$ & 0.004 & $0.074^{b}$ & 0.004 & $0.206^{\mathrm{c}}$ & 0.004 \\
\hline \multicolumn{7}{|l|}{ Apparent digestibility (\%) } \\
\hline DM & $84 \cdot 5^{a}$ & $0 \cdot 2$ & $71 \cdot 9^{b}$ & $0 \cdot 2$ & $53 \cdot 6^{\mathrm{c}}$ & 0.2 \\
\hline NDF & $46 \cdot 6^{a}$ & 0.7 & $46 \cdot 8^{\mathrm{a}}$ & 0.7 & $37 \cdot 5^{\mathrm{b}}$ & 0.7 \\
\hline ADF & $11 \cdot 7^{\mathrm{a}}$ & 0.9 & $28 \cdot 8^{\mathrm{b}}$ & 0.9 & $27 \cdot 1^{\mathrm{b}}$ & 0.9 \\
\hline Transit time (h) & $6 \cdot 5^{\mathrm{ab}}$ & 0.2 & $7 \cdot 2^{\mathrm{a}}$ & $0-2$ & $6 \cdot 2^{b}$ & 0.2 \\
\hline
\end{tabular}

a, b, c Mean values within rows with different superscript letters were significantly different $(P<0.05)$.

F2, mouse diet; GP1, guinea-pig diet; LU, lucerne (Medicago sativa) diet; $\mathrm{W}^{0 \cdot 75}$, metabolic body size, where $\mathrm{W}$ is body wt; $\mathrm{ADF}$, acid-detergent fibre.

* Calculated using LSMEANS statement of GLM of Statistical Analysis Systems (1985).

$\dagger$ For details of diets and procedures, see Table 1 and pp. 834-835.

GTC and TW, however, showed the opposite tendency. All values TW and GTC were the highest with diet LU, except for TW of small intestine. GTC of small intestine, caecum and colon were lowest with diet F2. The differences between diets were larger for GTC than for TW. Large differences between GTC and TW were observed for the small intestine, caecum and colon.

\section{Digestion trials}

The digestion characteristics (DM intake, digestible DM, NDF and ADF intakes and DM, NDF and ADF digestibility) were not significantly affected by sex and age. The digesta transit time was not affected by sex. DM intake was highest with diet LU and lowest with diet F2 (Table 3). Digestible DM intake showed a different response from that for DM intake. Digestible DM intake was highest with diet LU, but was not significantly different between diets F2 and GP1. DM digestibility was highest with diet F2 and lowest with diet LU. On the other hand, NDF digestibility was similar for diets F2 and GP1, with that for diet LU being lower (Table 3). The effect of diet on ADF digestibility differed from the effects on DM and NDF digestibilities; ADF digestibility of diet F2 was particularly low but those of diets GP1 and LU were similar. The transit time was significantly longer for diet GP1 than that for diet LU $(P<0.05)$. The differences in transit times between diet F2 and the other diets were not significant.

\section{Relationship between development of the gastrointestinal tract and diet utilization}

The correlation coefficients between gastrointestinal-tract characteristics and the seven digestion characteristics are shown in Table 4. DM and NDF digestibilities were negatively correlated with gastrointestinal-tract characteristics whereas all other correlations were positive. All correlation coefficients were high except that for TW of the small intestine. The digestion characteristics generally had higher correlations with GTC than with TW. The differences were particularly large in small intestine. 
Table 4. Correlation coefficients $\dagger$ among tissue weight (TW), gastrointestinal-tract capacity (GTC) and digestion characteristics for Syrian hamsters (Mesocricetus auretus) given diets differing in neutral-detergent-fibre (NDF) content

\begin{tabular}{|c|c|c|c|c|c|c|c|}
\hline & \multirow{2}{*}{$\frac{\text { Intake }}{\text { DM }}$} & \multicolumn{3}{|c|}{ Intake of digestible: } & \multicolumn{3}{|c|}{ Digestibility } \\
\hline & & DM & NDF & ADF & DM & NDF & ADF \\
\hline \multicolumn{8}{|l|}{ TW } \\
\hline Forestomach & $0.65^{* *}$ & $0.51 * *$ & $0.65^{* *}$ & $0.65^{* *}$ & $-0 \cdot 60^{* *}$ & $-0.46^{* *}$ & $0 \cdot 37^{* *}$ \\
\hline Glandular stomach & $0.72^{* *}$ & $0.51^{* *}$ & $0.73^{* *}$ & $0.71^{* *}$ & $-0 \cdot 70^{* *}$ & $-0.59^{* *}$ & $0.36^{* *}$ \\
\hline Small intestine & 0.04 & $0 \cdot 15$ & -0.02 & -0.01 & 0.04 & $-0 \cdot 11$ & -0.09 \\
\hline Caecum & $0.70^{* *}$ & $0 \cdot 48^{* *}$ & $0.67^{* *}$ & $0.67^{* *}$ & $-0.67^{* *}$ & $-0.62^{* *}$ & $0.33^{* *}$ \\
\hline Colon & $0.59 * *$ & $0.48 * *$ & $0.55^{* *}$ & $0.55^{* *}$ & $-0.55^{* *}$ & $-0.57^{* *}$ & $0.27^{*}$ \\
\hline \multicolumn{8}{|l|}{ GTC } \\
\hline Forestomach & $0.71^{* *}$ & $0.52^{* *}$ & $0.70^{* *}$ & $0.73^{* *}$ & $-0.69^{* *}$ & $-0.60^{* *}$ & $0.43^{* *}$ \\
\hline Glandular stomach & $0.72 * *$ & $0.53^{* *}$ & $0.70^{* *}$ & $0 \cdot 70^{* *}$ & $-0 \cdot 69 * *$ & $-0.56^{* *}$ & $0.38^{* *}$ \\
\hline Small intestine & $0.77^{* *}$ & $0.47^{* *}$ & $0.78^{* *}$ & $0.77^{* * *}$ & $-0.79^{* *}$ & $-0.65^{* *}$ & $0.41^{* *}$ \\
\hline Caecum & $0.88 * *$ & $0.58^{* *}$ & $0.89^{* *}$ & $0.87^{* *}$ & $-0.90^{* *}$ & $-0.70^{* *}$ & $0.49 * *$ \\
\hline Colon & $0.85^{* *}$ & $0.56^{* *}$ & $0.87^{* *}$ & $0.84^{* *}$ & $-0.86^{* *}$ & $-0.68^{* *}$ & $0.44^{* *}$ \\
\hline
\end{tabular}

$* P<0.05 ; * * P<0.01$.

† Calculated using correlation (CORR) of Statistical Analysis Systems (1985).

¥ For details of diets and procedures, see Table 1 and pp. 834-835.

\section{DISCUSSION}

In the present study we have developed the agar-fill method for measuring GTC. According to Herd \& Harrop (1978), the internal pressure of the gastrointestinal tract usually does not exceed $10 \mathrm{~mm} \mathrm{Hg}$ in vivo. The GTC measured by the agar-fill method was higher than that of the live animal, as this method used high pressure for agar fill. Thus, the value obtained using the agar-fill method might represent the maximum capacity of gastrointestinal tract. Herd \& Harrop (1978) suggested that GTC did not increase with increasing internal pressure after the pressure exceeded a certain level. The agar-fill method might use this level of internal pressure. The agar-fill method has the advantage over the water-fill method because it requires simple equipment and techniques and is easier to apply. We were unable to measure GTC of forestomach, glandular stomach and small intestine by the water-fill method, because they were too small or too weak to be tied or to be filled with water.

GTC for all compartments increased with increasing NDF content of diet. This tendency was particularly marked in small intestine, caecum and colon. A similar trend was observed for TW. TW and/or the length of the compartment in gastrointestinal tract have been reported to increase with increasing NDF content in pigs (Kass et al. 1961; Pond et al. 1981 ; Stanogias \& Pearce, 1985), in rats (Brown et al. 1979) and in rabbits (Gidenne, 1992). A difference in NDF sources has, also, been shown to affect the size of the gastrointestinal tract (Komai \& Kimura, 1980; Van Soest, 1984; Stanogias \& Pearce, 1985). In the present study the diets were made from similar NDF sources (diet GP1 was produced from similar raw materials to those of diets $\mathrm{F} 2$ and $\mathrm{LU}$ ). Thus, NDF source was considered to have no significant effect on the size of gastrointestinal tract in the present experiment.

DM digestibility decreased with increasing NDF content in diet. On the other hand, DM intake increased with increasing NDF content. Consequently, even though digestibility decreased, digestible DM intake did not decrease. Digestible DM intake of diet LU was the highest of the three diets although diet LU had the highest NDF content. The increase in 
DM intake was thought to be a result of compensation to maintain the digestible DM intake with a low-digestible-DM diet due to the high NDF content. Similar results have been obtained for pigs (Ehile et al. 1982; Frank et al. 1983) and cows (Hoover, 1986).

The NDF and ADF digestibilities did not decrease with increasing NDF content in diet (in contrast to the response of DM digestibility to dietary NDF content). NDF digestibility was similar for diets F2 and GP1, although the NDF content of diet GP1 was higher than that of diet F2. ADF digestibility of diet F2 was the lowest of the three diets. Mould et al. (1984) pointed out that when starch is added to the diet the digestibility of fibre is lowered by reduced rumen $\mathrm{pH}$ and decreased cellulolytic organisms. Hoover (1986) reported that a rumen $\mathrm{pH}$ lower than 6.0 reduced cellulolytic microbes and severely limited fibre digestion. Frank et al. (1983) showed that increasing the NDF content of the diet did not affect hemicellulose digestibility. Keys \& DeBarthe (1974) and Kass et al. (1980) showed that hemicellulose disappeared due to enzymic hydrolysis occurring before the caecum. They also reported that hemicellulose digestion in pigs was not affected by the level of dietary NDF and the reduction in microbial activity. Robertson et al. (1987) reported that the disappearance of dietary fibre was caused by microbial activity in the large intestine. The microbial degradation of fibre was expected to depend on its residence time in the large intestine, the type and the number of micro-organisms present, and the physical and chemical characteristics of the fibre source. Ehile et al. (1982) reported that fibre digestion was related to the rate of passage. But in the present study the transit time was found to have no correlation with the NDF content of the diet, although both DM intake and DM digestibility were affected by the NDF content of the diet. These results suggested that the increase in GTC with increasing NDF content was related to compensation for increased energy uptake when transit time remained constant.

Gidenne (1992) reported that a positive correlation exists between GTC and fibre degradation, and that enlargement of the caecum and colon contributed to the high capacity for fibre degradation in rabbits. The results of the correlation analysis revealed a relationship between the development of gastrointestinal tract and diet utilization (Table 4). The agreement between our findings and those of Gidenne (1992) suggests that the agarfill method is a useful tool for measuring GTC and offers an excellent means for studying the relationship between the development of gastrointestinal tract and changes in digestion.

The authors are grateful to Dr M. Minezawa of National Institute of Animal Industry and Dr C. Y. Lin of the Centre for Food and Animal Research for reading the manuscript and offering valuable comments.

\section{REFERENCES}

Abe, A. (1988). Feed analyses based on the carbohydrates and its application to the nutritive value of feeds. Memoirs of National Institute of Animal Industry no. 2. Inashiki-gun, Ibaraki, Japan: National Institute of Animal Industry.

Brown, R. C., Kelleher, J. \& Losowsky, M. S. (1979). The effect of pectin on the structure and function of the rat small intestine. British Journal of Nutrition 42, 357-365.

Ehile, F. R., Jeraci, J. L., Robertson, J. B. \& Van Soest, P. J. (1982). The influence of dietary fiber on digestibility, rate of passage and gastrointestinal fermentation in pigs. Journal of Animal Science 55, 1071-1081.

Frank, G. R., Aherne, F. X. \& Jensen, A. H. (1983). A study of the relationship between performance and dietary component digestibility by swine fed different levels of dietary fiber. Journal of Animal Science 57, 645-654.

Gidenne, T. (1992). Effect of fibre level, particle size and adaptation period on digestibility and rate of passage as measured at the ileum and in the faeces in the adult rabbit. British Journal of Nutrition 67, $133-146$.

Herd, R. M. \& Harrop, C. J. F. (1978). Estimation of stomach and caecal volumes in the brush-tailed possum, Trichosurus vulpecula, and the rabbit, Oryctolagus cuniculus. Australian Journal of Zoology 26, 621-628.

Hoover, W. H. (1986). Chemical factors involved in ruminal fiber digestion. Journal of Dairy Science 69, 27552766 . 
Kass, M. L., Van Soest, P. J., Pond, W. G., Lewis, B. L. \& McDowell, R. E. (1980). Utilization of dietary fiber from alfalfa by growing swine. I. Apparent digestibility of diet components in specific segments of the gastrointestinal tract. Journal of Animal Science 50, 175-191.

Keys, J. E. Jr \& DeBarthe, J. V. (1974). Site and extent of carbohydrate, dry matter, energy and protein digestion and the rate of passage of grain diets in swine. Journal of Animal Science 39, 57-62.

Komai, M. \& Kimura, S. (1980). Gastrointestinal responses to graded levels of cellulose feeding in conventional and germfree mice. Journal of Nutrition Science and Vitaminology 26, 389-399.

Mould, F. L., Ørskov, E. R. \& Gauld, S. A. (1984). Associative effects of mixed feeds. II. The effect of dietary additions of bicarbonate salts on the voluntary intake and digestibility of diets containing various proportions of hay and barley. Animal Feed Science Technology 10, 31.

Pond, W. G., Yen, J. T., Lindvall, R. N. \& Hill, D. (1981). Dietary alfalfa meal for genetically obese and lean growing pigs; Effect on body weight gain and carcass and gastrointestinal tract measurements and blood measurements. Journal of Animal Science 51, 367-373.

Robertson, J. A., Murison, S. D. \& Chesson, A. (1987). Estimation of the potential digestibility and rate of degradation of water-insoluble dietary fiber in the pig cecum with a modified nylon bag technique. Journal of Nutrition 117, 1402-1409.

Sakaguchi, E., Itoh, H., Uchida, S. \& Horigome, T. (1987). Comparison of fiber digestion and digesta retention time between rabbits, guinea-pigs, rats and hamsters. British Journal of Nutrition 58, 149-158.

Statistical Analysis Systems (1985). SAS User's Guide Version 5, pp. 434-506. Cory, NC: SAS Institute Inc.

Stanogias, G. \& Pearce, G. R. (1985). The digestion of fiber by pigs. III. Effects of the amount and type of fibre on physical characteristics of segments of the gastrointestinal tract. British Journal of Nutrition 53, 537-548.

Van Soest, P. J. (1984). Some physical characteristics of dietary fibres and their influence on the microbial ecology of the human colon. Proceedings of the Nutrition Society 43, 25-33. 